\title{
Surdez, educação e trabalho
}

\author{
Deafness, education and work
}

Sordera, educación y trabajo

\author{
Valéria Simplício da Silva \\ Doutoranda na Universidade Federal da Bahia, Salvador, Bahia, Brasil. \\ vsimplicyo@hotmail.com \\ ORCID - https://orcid.org/0000-0002-0904-6617
}

\author{
Miguel Angel Garcia Bordas \\ Professor doutor na Universidade Federal da Bahia, Salvador, Bahia, Brasil. \\ magbordas@gmail.com \\ ORCID - https://orcid.org/0000-0001-5970-9581
}

Recebido em 14 de fevereiro2019

Aprovado em 26 de dezembro 2019

Publicado em 9 de março de 2020

\section{RESUMO}

O presente trabalho tem como objetivo mostrar um panorama do estado da arte das produções acadêmicas, cuja temática relaciona a formação educacional dos surdos e sua atuação no mercado de trabalho, com a finalidade é obter um aprofundamento no processo investigativo da pesquisa de campo, que faz parte de uma pesquisa de Doutoramento, intitulada $O$ surdo, a educação e o trabalho: uma análise dessa tríade no mercado de trabalho em Aracaju/Se. Para a realização da coleta de dados foi consultado o Banco de Teses e Dissertações da Coordenação de Aperfeiçoamento de Pessoal de Nível Superior (CAPES). O período da busca foi demarcado, inicialmente, pelo último ano em que estavam disponíveis as informações no Banco de Teses, ou seja, 2018, e retrocedendo-se cinco anos, temos como corte inicial o ano de 2014. No entanto, tendo identificado apenas uma produção relacionada a esta temática, foi realizada outra busca, de forma geral, sem delimitar período, com o intuito de obter um número maior de trabalhos publicados. Para a organização dos dados coletados e a fim de analisar 0 corpus encontrado, foram definidas duas categorias de análise: (i) tipos de pesquisa; e (ii) abordagem teórica. A sistematização dos dados foi feita a partir de quadros por considerar-se que os dados neles apresentados consolidam uma análise quantitativa e descritiva. A pesquisa em questão nos permite conhecer a não evolução das produções que relacionam surdez, educação e trabalho, pois a caracterização das produções aponta temas silenciados, evidenciando a necessidade de novas investigações na área.

Palavras-chave: Educação; Surdez; Trabalho.

\section{ABSTRACT}

The present work aims to show an overview of the state of the art of academic productions, whose theme relates the educational background of the deaf and its work in the labor market, with the purpose is to obtain a deepening in the research process of field research, which makes part of a PhD research, entitled Deafness, education and work: an analysis of this triad in the labor market in Aracaju / Se. For the collection of data, the Bank of Theses and Dissertations of the Coordination of Improvement of Higher Level Personnel 
(CAPES) was consulted. The search period was initially demarcated by the last year in which the information was available at the Theses Bank, that is, 2018, and five years later, we have as initial cut the year 2014. However, having identified only a production related to this theme, another search was carried out, in general, without delimiting the period, in order to obtain a larger number of published works. For the organization of the data collected and in order to analyze the corpus found, two categories of analysis were defined: (i) types of research; and (ii) theoretical approach. The systematization of the data was done from tables because it was considered that the data presented in them consolidated a quantitative and descriptive analysis. The research in question allows us to know the non-evolution of productions that relate deafness, education and work, since the characterization of productions points to silenced themes, evidencing the need for new investigations in the area.

Keywords: Education; Deafness; Work.

\section{RESUMEN}

El presente trabajotiene como objetivo mostrar un panorama del estado del arte de lasproducciones académicas, cuya temática relaciona laformación educativa de lossordos y suactuaciónenel mercado de trabajo, conlafinalidad de obtener una profundizaciónenelproceso investigativo de lainvestigación de campo, que hace parte de una investigación de Doctorado, titulada El sordo, laeducación y eltrabajo: unanálisis de esa tríada enel mercado de trabajoen Aracaju / Se. Para larealización de larecolección de datosfue consultado el Banco de Tesis y Disertaciones de laCoordinación de Perfeccionamiento de Personal de Nivel Superior (CAPES). El período de labúsquedafue demarcado inicialmente por el último añoen que estabandisponibleslasinformacionesenel Banco de Tesis, es decir, 2018, y retrocediendo cinco años, tenemos como corte inicial elaño 2014. Sin embargo, habiendo identificado sólo una producción relacionada a esta temática, se realizóotrabúsqueda, de forma general, sin delimitar período, conel propósito de obtenerun número mayor de trabajos publicados. Para laorganización de losdatosrecolectados y para analizarel corpus encontrado, se definieron dos categorías de análisis: (i) tipos de investigación; y (ii) enfoque teórico. La sistematización de losdatos se hizo a partir de cuadros por considerar que losdatosenellos presentados consolidanunanálisiscuantitativo y descriptivo. La investigaciónencuestión nos permite conocerla no evolución de lasproducciones que relacionansordera, educación y trabajo, pueslacaracterización de lasproduccionesapunta temas silenciados, evidenciando lanecesidad de nuevasinvestigacionesenel área.

Palabras clave: Educación; Sordera; Trabajo.

\section{Introdução}

No mundo do ouvinte, as representações e imaginários construídos sobre o surdo são colonialistas (SKLIAR, 2005). A consequência disso é a percepção do surdo como ser inferior ao ouvinte, subalterno. Essa percepção passa a dominar o mundo ouvintista e, muitas vezes, o próprio surdo, que interioriza os estigmas e preconceitos dos ouvintes sobre si, levando-os a aceitar como normais a sua exclusão educacional e social, assim como o desenvolvimento de atividades laborais. 
http://dx.doi.org/10.5902/1984686X35960

Mesmo na atualidade, o estigma da incapacidade na deficiência sensorial, de certa forma, permanece e as dificuldades de acesso à informação, tanto na escolarização quanto na vida cotidiana desses sujeitos, refletem diretamente na competitividade no mercado de trabalho e na superação desses estigmas para que ocorra a verdadeira inclusão. A marginalização e a discriminação destes indivíduos ainda estão presentes na arquitetura, no dimensionamento do espaço urbano, nos transportes, no ensino, nos serviços de saúde, na organização do mercado de trabalho.

Os discursos que falam do surdo, enquanto trabalhador encontram-se emergidos em um discurso da deficiência, da falta, em que eficiência e competência são discursividades que, ao falar do surdo trabalhador, reafirmam discursos hegemônicos de uma sociedade ouvintista ${ }^{1}$.

Ao estudar a formação de surdos trabalhadores, Klein (2005) ressalta que esta se preocupa e atua especificamente como disciplinamento do sujeito surdo para melhor se adequar às necessidades do mundo do trabalho. A preocupação é com o treino comportamental para que o surdo se torne "aceitável" para a sociedade ouvinte.

Nesta perspectiva, vale ressaltar que as escolhas de atividades laborais para os surdos exercerem têm em comum o trabalho isolado ou seja, são atividades que, em sua maioria, não requerem o trabalho em grupo, que não exigem um nível de escolaridade mais elevado ou de uma comunicação mais constante e direta com o público, a exemplo da informática, considerada, pelos ouvintes, ideal para os surdos. Este fato relaciona-se com as representações que os ouvintes solidificaram sobre a pessoa surda e que se tornaram "naturais".

Diante deste contexto, bem como a partir da minha atuação como professora de Língua Brasileira de Sinais (Libras) da Universidade Federal de Sergipe (UFS), 0 interesse em realizar um estudo numa pesquisa de doutoramento foi desencadeado uma vez que, nessa atuação, mantenho contato constante com surdos trabalhadores dentro e fora da universidade, atuantes ou não no mercado de trabalho, vivenciando as suas discussões, indagações e lutas em questões relativas ao âmbito laboral.

Nesta perspectiva, é de extrema relevância um estudo das percepções dos surdos sobre os desafios que eles enfrentam para atuar no mercado de trabalho, levando em consideração sua formação e profissionalização, as políticas públicas de atuação das pessoas surdas no mercado formal de trabalho, bem como as lutas sociais e articulações dessa minoria, por meio dos Movimentos Sociais Surdos². 
http://dx.doi.org/10.5902/1984686X35960

Assim, esta pesquisa justifica-se por ser um tema atual e de grande relevância social que, devido à carência de estudos, merece ser analisado, aprofundando o corpo conceitual que vincula a integração e a valorização do surdo no mercado de trabalho e a inclusão social. Desta forma, essa pesquisa de doutoramento tem como objeto de estudo "a relação entre a formação educacional e a atuação dos surdos no mercado de trabalho em Aracaju/Se".

\section{Atuação dos surdos no mercado de trabalho: problematizando a questão}

De acordo o censo do Instituto Brasileiro de Geografia e Estatística (IBGE), o censo de 2010 mostra que 6,7\% da população brasileira possui algum tipo de deficiência. Os números apontam para um universo de 12,7 milhões de pessoas. Dentro desse universo, existem 10,7 milhões de pessoas com deficiência auditiva no país, onde $20 \%$ são completamente surdos.

Segundo dados do IBGE (2010), 13,1\% da população brasileira está desempregada. Em relação às pessoas com deficiência, a inclusão no mercado de trabalho ainda continua pequena. O trabalho para essas pessoas corresponde a somente $3,45 \%$ dessa população.

O levantamento do Cadastro Geral de Empregados e Desempregados (CAGED) de 2018 apontou 442.007 empregos para pessoas com deficiência - o que explica a baixa porcentagem.

De acordo com o Instituto Locomotiva de Pesquisa e Estratégia, em pesquisa realizada em 2019, apenas 37\% das pessoas com deficiência auditiva está atuando no mercado de trabalho.

O Brasil tem uma das menores taxas de participação de surdos no mercado de trabalho (VIANA, 2009). Já sob o olhar acadêmico, ainda persevera uma lacuna de estudos que deem voz ao público em questão, no sentido de apreender suas dificuldades em atuar no mercado de trabalho. E as limitações nem sempre estão nos surdos, mas no nível gerencial, no qual alguns profissionais tapam os ouvidos para não aceitar a nova geração que está lutando a fim de conquistar os seusdireitos.

Mesmo após as leis específicas que legitimam o direito de pessoas com deficiência ao trabalho, como a Lei $n^{\circ} 8.112$ de 11 de Dezembro de 1990, que determina a reserva de $20 \%$ das vagas em concursos públicos, e a Lei $n^{\circ} 8.213 / 91$ que obriga empresas com 
http://dx.doi.org/10.5902/1984686X35960

100 (cem) ou mais funcionários a reservarem de $2 \%$ a $5 \%$ das vagas para pessoas com deficiência, muitas empresas não contratam o surdo, alegando que a maioria possui baixa escolaridade, falta de capacitação profissional e dificuldade de comunicação com ouvintes.

No âmbito profissional, os surdos sofrem discriminação, não apenas no ingresso e permanência no mercado de trabalho, mas também no que diz respeito à sua capacidade de exercer e ocupar função compatível com seu perfil curricular e/ou qualificação profissional. As empresas têm colocado esses indivíduos no chamado "setor do barulho", sem ao menos avaliar os talentos ou qualificações que podem ter a oferecer; batem 0 carimbo de aprovado apenas para atender às exigências do Governo com base na Lei de Cotas.

O processo de contratação de pessoas com deficiência com um histórico de formação também deficiente torna-se um impeditivo inesperado nesta lógica contraditória de acumulação de capital, que força a empresa a inverter o processo, dispensando energia não na apropriação do trabalho, mas no desenvolvimento de um profissional que idealmente deveria ingressar com o mínimo de formação.

No entanto, na última década, dos surdos que têm completado a sua escolarização, uma parcela tem chegado à universidade ou participa de programas de profissionalização (SANTIAGO, 2011). Ainda de acordo com aautora:

$\mathrm{Na}$ comunidade surda, os jovens vêm se preparando para o mercado de trabalho, muitos deles, já na universidade, procuram profissões às quais possam depois exercer, independentemente da sua condição bilíngue (uso da língua de sinais como primeira língua e o Português escrito como segunda língua) (SANTIAGO, 2011, p. 16).

De acordo com uma pesquisa realizada por Santiago (2011), em uma instituição universitária privada da grande São Paulo, que proporciona aos alunos surdos cursar 0 ensino superior com o serviço especializado de Tradutores/Intérpretes de Língua de Sinais nas aulas, acompanhamento pedagógico e orientação educacional, mostrou que, dentre as 24 opções de cursos de graduação e 14 cursos tecnológicos, existem surdos matriculados em dez cursos diferentes. São eles: Administração, Ciências Contábeis, Engenharia da Computação, Engenharia de Produção, Pedagogia, Técnico em Análise e Desenvolvimento de Sistemas, Técnico em Design Gráfico, Técnico em Aeronave, Técnico em Recursos Humanos, Técnico em Rede de Computadores. 
http://dx.doi.org/10.5902/1984686X35960

Isso mostra que os jovens surdos acabam por escolher cursos levando em consideração que sua condição linguística não seja, no futuro, um impeditivo para a sua atuação profissional, demonstrando a possibilidade do surdo se adaptar ao mercado de acordo com as especificidades de sua condição linguística, bem como sua capacidade de inserção no mercado de trabalho, desde que a ele sejam dadas condições e oportunidade (SANTIAGO, 2011).

Neste sentido, percebe-se que os surdos se esforçam para realmente participarem da lógica do mercado de trabalho, no entanto a sua contratação ainda é muito tímida, e quando essas contratações ocorrem, em sua maioria, não é levada em conta a formação inicial e/ou técnica profissional destes sujeitos, impedindo-os do exercício de suas habilidades (PASTORE,2000).

Diantedestecontexto,expõem-se as questões norteadoras da pesquisa de doutoramento: por que a contratação de surdos no mercado de trabalho ainda é muito tímida, apesar do ingresso à universidade ou da participação deles em programas de profissionalização ter aumentado na última década? Qual a relação existente entre a formação educacional e/ou técnica profissional e a atuação dos surdos no mercado de trabalho? Como as políticas públicas, juntamente com os movimentos sociais desta minoria social,têm serevelado,no que se refere à atuação dos surdos no mercado de trabalho? Quais as dificuldadese/ou empecilhos que se apresentam para essa atuação? Que funções e/ou cargos os surdos têm exercido no mercado de trabalho?

A partir da problemática evidenciada e dos questionamentos expostos, apresenta-se a seguinte pergunta de pesquisa: em que medida a formação educacional e/ou técnica profissional dos surdos têm se revelado eficazes paraa inserção, permanência e atuação deles no mercado de trabalho, na atualidade, em Aracaju/SE?

Para elucidar as indagações acima foi estabelecido o objetivo geral: analisar as relações existentes entre a formação educacional e/ou profissional dos surdos e a sua atuação no mercado de trabalho em Aracaju/SE. E os específicos: identificar a formação e qualificação profissional dos surdos relacionando com os segmentos, áreas profissionais e funções mais exercidas por eles no mercado de trabalho; verificar as dificuldades e/ou empecilhos enfrentados pelos surdos para inserção e permanência e atuação no mercado de trabalho; averiguar as articulações da comunidade surda por melhores empregos e condições de trabalho; relacionar as atividades laborais desenvolvidas pelos surdos com suas aspirações profissionais. 
http://dx.doi.org/10.5902/1984686X35960

Nesta pesquisa, ao darmos voz aos surdos, faremos um estudo sobre as percepções deles sobre os desafios que enfrentam para atuar no mercado de trabalho, levando em consideração sua formação e profissionalização, as políticas públicas de atuação das pessoas surdas no mercado formal de trabalho,bem como as lutas sociais e articulações dessa minoria, por meio dos Movimentos Sociais Surdos.

O estudo deste tema evidencia a importância e a necessidade de estudos que contribuam para um conhecimento mais aprofundado da complexa realidade que envolve os surdos e o seu reconhecimento como sujeitos que possuem uma identidade e uma cultura próprias e como sujeitos de direitos que os caracterizam como cidadãos e como tal, livres para escolher e exercer a sua atividade profissional. Destarte, o tema aqui proposto possibilitará a análise e discussão a respeito das representações e imaginários sociais sobre o sujeito surdo e o seu processo de inclusão/exclusão no mercado de trabalho, contribuindo, desta forma, para o desvelar e o fortalecimento do processo de identidade da pessoa e da Comunidade Surda.

\section{Estado da arte das pesquisas que relacionam surdez, educação} trabalho

Estudar a realidade da atuação dos surdos no mercado de trabalho de Aracaju, compreendendo como se processa este fenômeno, dentro do contexto no qual se fundamenta este acontecimento nas suas várias manifestações e implicações, leva-nos a conhecê-lo por suas causas e explicá-lo pelos antecedentes e condicionantes.

Para a atuação no campo empírico, a pesquisa foi situada, primordialmente, como sendo um estudo de campo qualitativo, pelo qual o pesquisador buscará compreender o querer dizer de fenômenos humanos, com informações coletadas que não se expressam basicamente em números, ou cujo papel destes seja coadjuvante à análise principal. Aqui, portanto - e resumidamente -, a busca principal é pela descrição e pela busca do significado, não à frequência em que ocorre determinado fenômeno. (MOREIRA, 2002; GIL, 2008; COOPER; SCHINDLER, 2011).

A fenomenologia cuida investigar a essência das formas puras depensamento. Se a intenção da pesquisa é tecer considerações a respeito da formação educacional do surdo e de sua atuação no mercado de trabalho, é útil pensarmos na sua forma de entender omundo, de como ele compreende, vivencia e percebe a sua localização dentrodo ambiente laboral, de como ele vê a questão comunicativa, como sedescortina o seu 
http://dx.doi.org/10.5902/1984686X35960

mundo-da-vida. Pela profundidade dessas questões, é que afenomenologia é escolhida aqui, portanto, como método de investigação.Segundo Gamboa:

\begin{abstract}
Para a fenomenologia a ciência consiste na compreensão dos fenômenos em suas várias manifestações, na elucidação dos pressupostos, dos mecanismos ocultos, das implicações, dos contextos nos quais se fundamentam os fenômenos. A compreensão supõe a interpretação, quer dizer, revelar o sentido ou os sentidos, os significados que não se dão imediatamente, razão pela qual necessitamos da hermenêutica, da indagação, do esclarecimento das fases ocultas que se escondem atrás dos fenômenos. (GAMBOA, 2007, p. 88).
\end{abstract}

Para descrever de que se trata o método fenomenológico, principia-se pela definição dada por Triviños (1987), de que a fenomenologia se ocupa da essência, como as essências da consciência e da percepção.

A pesquisa fenomenológica tem por característica marcante a preocupação, por parte do pesquisador, de não buscar explicações por meio de leis, ou mesmo deduções: seu material de trabalho tem como principal fonte aquilo que lhe é dado pelos atores, considerando o que está na consciência dos sujeitos (GIL, 2008). Neste autor, encontramos uma definição bastante concisa daquilo que intenta 0 método fenomenológico:

[...] proporcionar uma descrição direta da experiência tal como ela é, sem nenhuma consideração acerca de sua gênese psicológica e das explicações causais que os especialistas podem dar. Para tanto, é necessário orientarse ao que é dado diretamente à consciência, com a exclusão de tudo aquilo quepode modificá-la, como o subjetivo do pesquisador e o objetivo que não é dado realmente no fenômeno considerado (GIL, 2008, p. 14).

Ainda segundo Gil (2008, p. 14-15), a realidade, do ponto de vista do método fenomenológico, refere-se ao que é compreendido e interpretado, e deve-se entender como o que surge da intencionalidade da consciência voltada para o fenômeno investigado, de forma que não se admite a existência de uma única realidade, senão tantas forem as suas comunicações e interpretações.

Para dar início a este estudo, primeiramente foi realizada uma pesquisa quantitativodescritiva no Banco de Teses e Dissertações da Capes, sobre estudos realizados no Brasil no período de 2014 a 2018 com a temática: Surdez, Educação e Trabalho, com o objetivo mostrar um panorama do estado da arte das produções acadêmicas cuja temática relaciona a formação educacional dos surdos e sua atuação no mercado de trabalho, e cuja finalidade é obter um aprofundamento no processo investigativo da pesquisa de campo, que faz parte de uma pesquisa de Doutoramento, cujo título é 
http://dx.doi.org/10.5902/1984686X35960

Surdez, educação e mercado de trabalho: uma análise dessa realidade social em Aracaju/Se. Essa pesquisa será realizada junto aos trabalhadores surdos na Comunidade Surda ${ }^{3}$ de Aracaju/SE, e fornecerá subsídios para o avanço das pesquisas nesta área.

Para a realização da coleta de dados foi consultado o Banco de Teses da Capes. $O$ período da busca foi demarcado, inicialmente, pelo último ano em que estavam disponíveis as informações no Banco de Teses, ou seja, 2018, e retrocedendo-se cinco anos, temos como corte inicial o ano de 2014.

Das produções desse período, apenas a dissertação de Roberto Antônio Alves, intitulada Ser surdo: o percurso (auto) biográfico das aprendizagens construídas na vida escolar e profissional, defendida em 2016 no Programa de Pós-Graduação Escolar da Universidade Estadual Paulista Júlio de Mesquita Filho/Araraquara, faz relação entre a surdez, a educação e o trabalho.

Desta forma, tendo identificado apenas uma produção relacionada a esta temática, no referido recorte temporal, foi realizada outra busca, de forma geral, sem delimitar período, com o intuito de obter um número maior de trabalhos publicados. Após este segundo levantamento, foram identificadas, até 2018, seis dissertações de mestrado, na área da Educação, defendidas em 1999, 2002, 2006, 2011 e 2016, cujos estudos relacionam a educação dos surdos e o trabalho.

O primeiro trabalho é o de Madalena Klein, A formação do surdo trabalhador: discursos sobre a surdez, a educação e o trabalho, defendido em 1999, no Programa de Pós-Graduaçãoem Educação da Universidade Federal do Rio Grande do Sul. Constatouse que esta autora é a que mais se dedicou à temática em questão, até este momento, uma vez que ela é a pesquisadora que mais tem publicações, em forma de artigos, com a temática Surdez, Educação e Trabalho, no entanto o texto de sua dissertação não está disponível para leitura na internet.

$\mathrm{Na}$ década de 1980, e ao longo dos anos 1990, as pesquisas científicas demonstrando o estatuto linguístico da língua de sinais no Brasil iniciaram-se, e a linha de argumentação dos ativistas surdos envolvidos com a luta pela oficialização da Libras, sustentou-se ainda mais no trabalho dos linguistas que demonstravam - por meio da publicação de livros, artigos e materiais didáticos e da organização de grupos de cursos, congressos e grupos de pesquisas - a natureza linguística desta língua (BRITO; NEVES; XAVIER, 2013, p. 95). Assim, a partir da década de 1990, houve um crescimento em relação ao número de trabalhos acadêmicos publicados, seja em forma de dissertações 
http://dx.doi.org/10.5902/1984686X35960

de mestrado, teses de doutorado, artigos científicos ou livros, e muitos abordavam aspectos referentes à educação de surdos.

Com a promulgação da Lei $n^{0}$ 10.436, de 2002, a Libras passa a ser reconhecida como língua oriunda de comunidades de pessoas surdas do Brasil e, por meio do Decreto n 5.626 de 2005 que a regulamenta, esse número de trabalhos aumenta, no entanto, como esta pesquisa evidencia, um número infinitamente pequeno desses trabalhos relaciona a educação de surdos e o trabalho laboral.

As seis produções acadêmicas encontradas nesta pesquisa foram selecionadas inicialmente pelo título e, a partir da sua inclusão por este critério, realizou-se a leitura do resumo de cada trabalho, de onde foram retiradas informações pertinentes à pesquisa.

Quadro 1: Produções acadêmicas sobre surdez, educação e trabalho

\begin{tabular}{|c|c|c|c|c|}
\hline TITULO/ANO & AUTORIA & $\begin{array}{l}\text { PROGRAMA/ } \\
\text { INSTITUIÇÃO/ } \\
\text { LOCAL }\end{array}$ & $\begin{array}{l}\text { ABORDAGEM } \\
\text { TEÓRICA }\end{array}$ & $\begin{array}{l}\text { MÉTODOS } \\
\text { TÉCNICAS } \\
\text { PESQUISA }\end{array}$ \\
\hline $\begin{array}{l}\text { Ser surdo: o percurso (auto) } \\
\text { biográfico das aprendizagens } \\
\text { construídas na vida escolar e } \\
\text { profissional } \\
\text { (2016) }\end{array}$ & $\begin{array}{l}\text { ALVES, } \\
\text { Roberto } \\
\text { Antônio }\end{array}$ & $\begin{array}{l}\text { Mestrado em } \\
\text { Educação Escolar } \\
\text { da Universidade } \\
\text { Estadual Paulista } \\
\text { Júlio de Mesquita } \\
\text { Filho/Araraquara }\end{array}$ & $\begin{array}{l}\text { Não } \\
\text { identificada no } \\
\text { trabalho }\end{array}$ & $\begin{array}{l}\text { Pesquisa } \\
\text { biográfica }\end{array}$ \\
\hline $\begin{array}{l}\text { O surdo e o mercado de } \\
\text { trabalho na cidade } \\
\text { Manaus } \\
\text { (2006) }\end{array}$ & $\begin{array}{l}\text { REIS, } \\
\text { Joab } \\
\text { Grana }\end{array}$ & $\begin{array}{lr}\text { Mestrado } & \text { em } \\
\text { Educação } & \text { da } \\
\text { Universidade } & \\
\text { Federal } & \text { do } \\
\text { Amazonas } & \end{array}$ & $\begin{array}{l}\text { Não } \\
\text { identificada no } \\
\text { trabalho }\end{array}$ & $\begin{array}{l}\text { Não identificada no } \\
\text { trabalho }\end{array}$ \\
\hline $\begin{array}{l}\text { A formação do surdo } \\
\text { trabalhador: discursos sobre } \\
\text { a surdez, a educação e o } \\
\text { trabalho } \\
\text { (1999) }\end{array}$ & $\begin{array}{l}\text { KLEIN, } \\
\text { Madalena }\end{array}$ & $\begin{array}{lr}\text { Mestrado em } \\
\text { Educação da } \\
\text { Universidade } \\
\text { Federal do Rio } \\
\text { Grande do Sul } \\
\end{array}$ & $\begin{array}{l}\text { Dissertação } \\
\text { não disponível } \\
\text { na internet }\end{array}$ & $\begin{array}{l}\text { Dissertação não } \\
\text { disponível na internet }\end{array}$ \\
\hline $\begin{array}{l}\text { Escolarização e inserção da } \\
\text { pessoa com deficiência } \\
\text { auditiva no mercado de } \\
\text { trabalho formal na cidade de } \\
\text { São Luís } \\
\text { (2011) }\end{array}$ & $\begin{array}{l}\text { AROUCH } \\
\text { A, Maria } \\
\text { José } \\
\text { Rabelo }\end{array}$ & $\begin{array}{lr}\text { Mestrado } & \text { em } \\
\text { Educação } & \text { da } \\
\text { Universidade } & \\
\text { Federal } & \text { do } \\
\text { Maranhão } & \end{array}$ & $\begin{array}{l}\text { Histórico- } \\
\text { crítico }\end{array}$ & $\begin{array}{l}\text { Pesquisa qualitativa } \\
\text { Estudo de caso. }\end{array}$ \\
\hline $\begin{array}{lrr}\text { Surdez } & \text { e } & \text { inserção } \\
\text { profissional: } & \text { representações } \\
\text { sociais de } & \text { universitários } \\
\text { surdos } & & \\
\text { (2011) } & \end{array}$ & $\begin{array}{l}\text { MAGALDI } \\
\text { 'José } \\
\text { Carlos } \\
\text { Miraglia }\end{array}$ & $\begin{array}{lr}\text { Mestrado } & \text { em } \\
\text { Educação } & \text { da } \\
\text { Universidade } & \\
\text { Estácio de Sá } & \end{array}$ & $\begin{array}{l}\text { Teoria das } \\
\text { representaçõe } \\
\text { s sociais }\end{array}$ & Pesquisa qualitativa \\
\hline $\begin{array}{l}\text { A qualificação dos } \\
\text { para o trabalho } \\
\text { para o o } \\
\text { significativo papel } \\
\text { linguagem (2002) }\end{array}$ & $\begin{array}{l}\text { ARAÚJO, } \\
\text { Maria } \\
\text { Antonieta } \\
\text { Nascimen } \\
\text { to }\end{array}$ & $\begin{array}{l}\text { Mestrado em } \\
\text { Educação da } \\
\text { Universidade } \\
\text { Federal da Bahia }\end{array}$ & $\begin{array}{l}\text { Não } \\
\text { identificada no } \\
\text { trabalho }\end{array}$ & Estudo de Caso \\
\hline
\end{tabular}

Fonte: Elaborado pela autora a partir do Banco de Teses e Dissertações da Capes, 2019. 
Para a organização e investigação dos dados coletados e a fim de analisar o corpus encontrado, foram definidas duas categorias de análise: (i) tipos de pesquisa; e (ii) abordagem teórica. A sistematização dos dados ocorreu a partir de tabelas por considerar-se que os dados nelas apresentados consolidam uma análise quantitativa e descritiva.

A primeira categoria de análise refere-se ao tipo de pesquisa definida no trabalho. Gil (1996, p. 19) destaca que uma pesquisa, ao ser desenvolvida, deve levar em consideração "os conhecimentos disponíveis e a utilização cuidadosa de métodos, técnicas e outros procedimentos científicos". Assim sendo, temos a seguinte configuração no que tange ao tipo de pesquisa das produções:

Quadro 2: Tipos de pesquisa por ano e quantidade

\begin{tabular}{|l|l|l|}
\hline ANO & QUANTIDADE & TIPOLOGIA \\
\hline 2002 & 01 & Estudo de Caso \\
\hline 2006 & 01 & Sem descrição \\
\hline 2011 & 01 & Qualitativa \\
\hline 2011 & 01 & Estudo de Caso \\
\hline 2016 & 01 & (Auto) biográfica \\
\hline
\end{tabular}

Fonte: Elaborado pela autora a partir do Banco de Teses e Dissertações da Capes, 2019.

Diante de um corpus de cinco trabalhos de pesquisa, foram identificadas quatro tipologias de pesquisa diferentes com destaque para o fato de que, em uma das produções, não é definido ou especificado o tipo de pesquisa realizado.

A segunda categoria de análise refere-se à abordagem teórica que dá embasamento à pesquisa.

Quadro 3: Abordagem teórica por ano e quantidade

\begin{tabular}{|l|l|l|}
\hline ANO & QUANTIDADE & TEORIA \\
\hline 2002 & 01 & Sem definição \\
\hline 2006 & 01 & Sem definição \\
\hline 2011 & 01 & Teoria das Representações \\
\hline 2011 & 01 & Histórico-crítica \\
\hline 2016 & 01 & Sem definição \\
\hline
\end{tabular}

Fonte: Elaborado pela autora a partir do Banco de Teses e Dissertações da Capes, 2019. 
Conforme os dados acima, podemos constatar que a maioria dos trabalhos encontrados não define uma abordagem teórica específica para fazer o embasamento da pesquisa, o que nos leva à compreensão de que os referidos estudos foram realizados considerando o reconhecimento da complexidade e da heterogeneidade inerentes às práticas educativas que estão sempre na perspectiva de uma pluralidade de olhares e linguagens, reconhecida como necessária à compreensão da suposta complexidade da educação. De acordo com Pellanda (1996), essa abordagem multirreferencial é constituída como uma abertura para "olhares múltiplos" com vistas a "romper com a hegemonia epistêmica dos grandes saberes.

A pesquisa em questão nos permite conhecer a não evolução das produções que relacionam surdez, educação e trabalho, pois a caracterização desses cinco anos de produção aponta temas silenciados, evidenciando a necessidade de novas investigações na área.

Cabe ressaltar que uma significativa parte dos resumos das produções apresentava limitações para a descrição teórico-metodológica, o que impõe um desafio quanto à qualidade dos resumos das pesquisas que constam neste banco de dados. Assim, é fundamental que os resumos apresentem elementos centrais do trabalho científico que possibilitem que outros pesquisadores conheçam as produções e encontrem interlocutores para suas investigações.

\section{Considerações finais}

Considerando que no âmbito profissional os surdos sofrem discriminação, não apenas no ingresso e permanência no mercado de trabalho, mas também no que diz respeito à sua capacidade de exercer e ocupar função compatível com seu perfil curricular e/ou qualificação profissional, é de extrema relevância um estudo das percepções dos surdos sobre os desafios que eles enfrentam para atuar no mercado de trabalho, levando em consideração sua formação e profissionalização.

A atuação das pessoas surdas deve ser vista como qualquer outra, desde o que se espera do trabalhador como a dedicação, o profissionalismo, o compromisso com a missão e política da organização, ou seja, atributos necessários para todo o empregado, pois o surdo não espera mais o assistencialismo, mas também oportunidade de mostrar sua potencialidade ao trabalhar e desenvolver atividades, almejando crescimento pessoal, 
http://dx.doi.org/10.5902/1984686X35960

com igual oportunidade nas funções oferecidas pelas empresas no processo de contratação.

Neste sentido, algumas transformações seriam necessárias para a garantia de melhores oportunidades e equidade de atuação dos surdos no mercado de trabalho, como a promoção de políticas públicas educacionais mais atuantes que garantam ao surdo o direito a uma educação com qualidade e, consequentemente, uma boa formação, respeito das empresas quanto às diferenças, bem como responsabilidade social não somente com relação à contratação, mas também à promoção de capacitação profissional, assim como uma estrutura física para que os surdos possam desenvolver seu potencial produtivo e permanecer na empresa.

Nesta pesquisa, ao darmos voz aos surdos, faremos um estudo acerca das suas percepções sobre os desafios que enfrentam para atuar no mercado de trabalho, levando em consideração sua formação e profissionalização, as políticas públicas de atuação das pessoas surdas no mercado formal de trabalho, bem como as lutas sociais e articulações dessa minoria, por meio dos MovimentosSociaisSurdos.

Por isso, as implicações do presente estudo se colocam para a academia, para as organizações e para a sociedade brasileira como um todo. No que diz respeito à academia, cabe aos pesquisadores buscarem compreender melhor a realidade de todos os segmentos que compõem a força de trabalho, cada vez mais complexa e heterogênea, e na qual há minorias, cujas vozes são silenciadas pelos discursos organizacionais.

Já no que tange às organizações, há a necessidade de uma melhor compreensão por parte dos seus administradores destas múltiplas realidades, de modo que possam formular políticas e práticas organizacionais condicentes à melhoria da qualidade de vida, condições de trabalho e dignidade de todos os empregados, deficientes ou não.

Em relação à sociedade, espera-se que ela seja responsável pelo reconhecimento da cidadania de todos os brasileiros. Avançar por estas implicações parece ser uma adequada sugestão para futuras agendas de pesquisas.

\section{Referências}

BRASIL. Lei no 10.436 de 24 de abril de 2002. Brasília: Presidência da República, Casa Civil, Subchefia para Assuntos Jurídicos.

BRASIL, Ministério da Educação. Secretaria da Educação Especial. Decreto no 5.626, de 22 de dezembro de 2005. Regulamenta a Lei n 10.436, de 24 de abril de 2002. Diário Oficial da União, Brasília, DF, 23 dez. 2005. Disponível em: 
http://www.presidencia.gov.br/ccivil/ Acesso em: 20 abr. 2018.

BRASIL. Ministério do Emprego e do Trabalho. Lei 8.213 de 24 de julho de 1991. Legislação relativa ao trabalho de pessoas portadoras de deficiência: coletânea. Brasília: TEM SIT/DSST, 1999.

BRASIL. Lei no 8.112 de 11 de dezembro de 1990.Brasília: Presidência da República, Casa Civil, Subchefia para Assuntos Jurídicos.

BRITO, Fábio Bezerra; NEVES, Sylvia Lia Grespan; XAVIER, André Nogueira. O movimento surdo e sua luta pelo reconhecimento da LIBRAS e pela construção de uma política linguística no Brasil. In: LIBRAS em estudo: política linguística. Neiva de Aquino Albres e Sylvia Lia Grespan (Org.). São Paulo: Editora FENEIS, 2013.

BRITO, Fábio Bezerra. O movimento surdo no Brasil: a busca por direitos. Journal of Research in Special Educational Needs, Volume 16, Number s1, 2016, p. 766-769. doi: 10.1111/1471-3802.12214.

BRASIL. Secretaria do Trabalho. Ministério da Economia.Cadastro Geral de Empregados e Desempregados - CAGED. (Disponível em: http://trabalho.gov.br/trabalhador-caged. Acesso em 14 de mai. 2019.

CAPES. Coordenação de Aperfeiçoamento de Pessoal de Nível Superior. Serviços: Banco de teses. 2018. Disponível em: http://catalogodeteses.capes.gov.br/catalogoteses/. Acesso em: maio/jun. 2018.

COOPER, Donald R.; SCHINDLER, Pamela S. Métodos de pesquisa em administração. 7. ed. São Paulo: Bookman, 2003.

GAMBOA, Silvio Sanchez. Pesquisa em educação: métodos e epistemologias. Chapecó: Argos, 2007.

GIL, Antônio Carlos. Métodos e técnicas de pesquisa social. São Paulo: Atlas, 2008.

GIL, Antônio Carlos ; SILVA, Sueli Percínio Moreira. O Método Fenomenológico na Pesquisa sobre Empreendedorismo no Brasil. Revista de Ciências da Administração, v. 17, n. 41, p. 99-113, abr. 2015.

GIL, Antonio Carlos. Como elaborar projetos de pesquisa. 3. ed. São Paulo: Editora Atlas S.A., 1996.

Instituto Brasileiro de Geografia e Estatística (IBGE). Censo 2010. Disponível em: https://censo2010.ibge.gov.br/. Acesso em 29 de jan. 2020.

KLEIN, Madalena. Cultura surda e inclusão no mercado de trabalho. In: SKLIAR, Carlos (Org.). A surdez: um olhar sobre as diferenças. 3. ed. Porto Alegre: Mediação, 2005.

MELUCCI, Alberto. Challenging codes: collective action in the information age.

Cambridge: Cambridge University Press, 1996. 
http://dx.doi.org/10.5902/1984686X35960

MOREIRA, Daniel A. O método fenomenológico na pesquisa. São Paulo: Pioneira Thomson, 2002.

PASTORE, Jose. Oportunidades de trabalho para portadores de deficiência. São Paulo. Editora LTr,2000.

PELLANDA, Nize Maria Campos. I Congresso Estadual de Educação Profissional: Perfil do trabalhador. Disponível em: https://books.google.com.br/books?id=tanwaqLXVvEC\&pg=PA32\&lpg=PA32\&dq=trabalho ++Pellanda+1996\&source=bl\&ots=2W5O6- .1996. Acesso em: 25 abr. 2019.

SACKS, Oliver. Vendo vozes: uma viagem ao mundo dos surdos. Tradução Laura Teixeira Motta. São Paulo: Companhia das Letras, 2005.

SANTIAGO, Vânia de Aquino Albres. A participação dos surdos no mercado de trabalho. Anhanguera Educacional, 2011. Disponível em:

http://www.porsinal. pt/index.php?ps=artigos\&idt=artc\&cat=12\&idart=299. Acesso em: 15 de jun. de 2017.

SKLIAR, Carlos Bernardo. (Org.). Os estudos surdos na educação: problematizando a normalidade. In: A surdez: um olhar sobre as diferenças. 6. ed. Porto Alegre: Mediação, 2005.

SKILIAR. Carlos. A surdez: um olhar sobre as diferenças. 3. ed. Editora Mediação. Porto Alegre. 1998.

TRIVIÑOS, Augusto Nibaldo Silva. Introdução à pesquisa em ciências sociais: a pesquisa qualitativa em Educação. São Paulo: Atlas, 1987.

VIANA, Alvanei dos Santos. A inserção dos surdos no mercado de trabalho: políticas públicas, práticas organizacionais e realidades subjetivas. 2009. Dissertação (Mestrado em Administração) - Universidade do Grande Rio, Duque de Caxias,2009.

\section{Notas}

${ }^{1}$ Ouvintismo é "um conjunto de representações dos ouvintes, a partir do qual o surdo está obrigado a olharse e a narrar-secomosefosseouvinte.Alémdisso, énesseolhar-se, enessenarrar-sequeacontece, mas percepçõesdoserdeficiente, do não ser ouvinte; percepções que legitimam as práticas terapêuticas habituais." (SKILIAR, 1998, p.15).

2 Segundo a teoria de Melucci (1996), o movimento social surdo brasileiro é entendido como um sistema composto de relações sociais envolvendo principalmente pessoas surdas, grupos e organizações de surdos - surgiu no começo da década de 1980, quando o país vivia um clima de reativação e expansão dos movimentos de diversos setores da sociedade, como operários, moradores de bairros populares, mulheres, negros e homossexuais, que decorria do processo de abertura política e redemocratização.

${ }^{3}$ Uma comunidade surda é um grupo de pessoas que vivem num determinado local, partilham os mesmos objetivos dos seus membros e que, por diversos meios, trabalham no sentido de alcançá-los. Uma comunidade surda pode incluir pessoas que não são surdas, mas que apoiam ativamente os objetivos dessa comunidade (PADDEN, 1980, p. 90 apud SACKS, 2005, p.155). 


\section{Correspondência}

Valéria Simplício da Silva - Universidade Federal de Sergipe, Centro de Educação de Ciências Humanas, Av. Marechal Rondon, S/N, Jardim Rosa Elze, São Cristóvão, Sergipe, Brasil.

CEP: $49100-000$

\section{(c) (i) \&}

4.0 International (CC BY-NC 4.0) 